\title{
Controlled study of ocular morbidity in school children born preterm
}

\author{
F G McGinnity, J H Bryars
}

\begin{abstract}
Two hundred children who were of very low birth weight (VLBW) (1500 g or less) and 193 controls who were of normal birth weight (NBW) were examined at approximately 9 years of age. Binocular visual acuity of $6 / 6$ or better was noted in $178(89 \cdot 5 \%)$ VLBW children and $189(97.9 \%)$ NBW children. Visual morbidity was significantly higher among VLBW children. Strabismus was present in $\mathbf{3 8}$ $(19 \%)$, cicatricial retinopathy of prematurity in $13(6 \cdot 5 \%)$, and optic atrophy in six (3\%) children in this group. Children who were VLBW were also more myopic than the NBW controls. Optic atrophy was frequently associated with cerebral dysfunction. Regular assessments to identify ocular abnormalities in children who were VLBW are recommended.

(Br f Ophthalmol 1992; 76: 520-524)
\end{abstract}

Advances in obstetric and neonatal care have significantly increased the survival of very low birth weight (VLBW) infants and in one area survival rates for these babies have improved from $35 \%$ to $72 \%$ between $1968-1972$ and 1979 1983. ${ }^{1}$ There has been considerable concern that the prevalence of neurosensory disorders among the survivors may also have increased ${ }^{2}$ and recent reports have shown a high incidence of ocular problems among children who were born preterm. ${ }^{34}$ However these studies were uncontrolled and performed on preschool children and do not give an accurate assessment of the visual performance of these children in relation to their contemporaries. The aim of this study was to compare the ophthalmological outcome of a group of children of school age who were VLBW with a control group of children who were full term infants.

\section{Patients and methods}

The study group comprised those infants of VLBW (1500 g or less), admitted to the neonatal intensive care unit (NICU) at the Royal Maternity Hospital, Belfast during the years 1978 to 1981 , who survived. During this period, 381 babies were admitted to this NICU and $243(64 \%)$ survived until discharge. A further five children died between discharge and the commencement of this study. Two hundred (84\%) of the 238 children were available for a follow-up ophthalmological examination at a mean age of $9 \cdot 1$ years (range $7 \cdot 2-11.3$ years). Of the 200 children examined $68(34 \%)$ had been transferred from another hospital during the neonatal period. Twenty children were extremely low birth weight (ELBW) - that is, weighing less than $1000 \mathrm{~g}$ and 49 were assessed as less than 28 weeks' gestation.
A control group of normal birth weight (NBW) children, who had weighed more than $2500 \mathrm{~g}$ at birth, was chosen. Each child in the VLBW group was matched with a child in the control group on sex of the child, date of birth, and social class. The distinguishing variables between the two groups were gestational age (preterm versus full term) and birth weight (less than $1500 \mathrm{~g}$ versus more than $2500 \mathrm{~g}$ ). In total the control group comprised 193 subjects. The mean age of the VLBW children at examination was $9 \cdot 10$ years $(\mathrm{SD}=1.05)$ and that of the NBW children was 8.82 years $(S D=1.02)$. The sex distribution of children in the two groups was roughly equal with 83 males and 117 females in the VLBW group. Using the registrar general's classification, there was no significant difference between the VLBW and NBW groups when social class was considered.

All eye examinations were performed by a single observer (FGMG). Where possible monocular and binocular visual acuities were tested using a Snellen chart. Visual acuity was classified as $\operatorname{good}(6 / 6$ or better), intermediate (6/9 to $6 / 12)$, or poor $(6 / 18$ or worse). Three children who were unable to comprehend the Snellen test were assessed with graded white balls from the Stycar vision testing set. ${ }^{5}$ Binocular reading vision was assessed using near test types. A comprehensive assessment of ocular motility was performed on each child. Details of previous orthoptic treatment were obtained from hospital records.

A cycloplegic refraction was carried out following the instillation of cyclopentolate $1 \%$ in both eyes. The spherical equivalent for each eye was calculated as the mean of the refraction values in the two principal meridians. The spherical equivalent value for each child was calculated as the mean of the spherical equivalents for each eye. Anterior segment examination with a slit-lamp and funduscopy with a direct ophthalmoscope were performed in all children. The peripheral fundus was examined with an indirect ophthalmoscope after pupillary dilatation. Regressed retinopathy of prematurity (ROP) findings were documented according to the scheme devised by the International Committee for the Classification of the Late Stages of ROP. ${ }^{6}$ Electrophysiology was performed, when necessary, to supplement the clinical examination.

Of the present cohort of 200 VLBW children, 191 had been examined by an ophthalmologist during the neonatal period. This included a fundal examination after pupillary dilatation. The presence of any ocular abnormality including ROP was noted at that time.

Data were analysed using the SPSS-X? statistical package on an IBM 3090 computer. Where a mean value was calculated the corres-

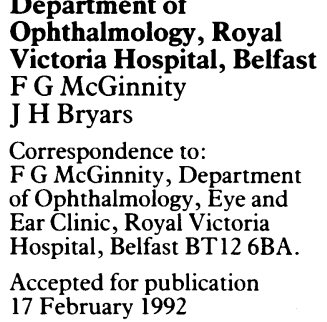


Table 1 Details of ophthalmic findings and mental retardation of VLBW children with poor binocular visual acuity

\begin{tabular}{lllll}
\hline Case no & Visual acuity & Ophthalmic findings & Mental handicap & Special schooling \\
\hline 1 & $6 / 18$ & none & Down's syndrome & yes \\
2 & $6 / 18$ & nystagmus & none & no \\
3 & $6 / 24$ & myopia & none & no \\
4 & $6 / 24$ & albinism & none & no \\
5 & $6 / 60$ & ROP & none & yes \\
6 & $6 / 60$ & none & yes & yes \\
7 & HM & optic atrophy & yes & yes \\
8 & HM & optic atrophy & yes & yes \\
9 & HM & optic atrophy & yes & yes \\
10 & NPL & optic atrophy & yes & yes \\
\hline
\end{tabular}

$H M=$ hand movements; $N P L=$ no perception of light $; R O P=$ retinopathy of prematurity.

ponding standard deviation (SD) was also noted. Where there was a significant difference the appropriate test and the significance level were cited. A test was considered not significant (NS) if it failed to reach the $p=0.05$ level.

\section{Results}

\section{VISUAL ACUITY}

Binocular visual acuity was assessed in 199 of 200 VLBW children and all of the NBW children. Vision assessment was not possible in one child with Down's syndrome. Visual acuity was significantly poorer in the VLBW group $\left(\chi^{2}=13 \cdot 51\right.$, $\mathrm{DF}=2, \mathrm{p}<0.001)$. Whereas $189(97.9 \%) \mathrm{NBW}$ children had $6 / 6$ vision or better, $178(89.5 \%)$ VLBW children had similar vision. No child in the NBW group had $6 / 18$ or poorer vision compared with $10(5 \cdot 1 \%)$ in the VLBW group. Table 1 lists details of the 10 children in the VLBW group with poor vision including significant ophthalmic findings, associated mental retardation, and whether special schooling was needed.

All of the children in the NBW group achieved a reading vision of $\mathrm{N} 5$. Reading vision could only be tested in $189(94.5 \%)$ children in the VLBW group because of poor cooperation. Of these only two children failed to read N5, one child reading N12, and the other N6. Overall, $188(94 \%)$ of the VLBW group had a reading vision of N6 or better.

Best corrected monocular visual acuity was assessed in 190 children in the VLBW group and all children in the NBW group. Three children in the VLBW group were excluded because it was not possible to test each eye separately and a further seven children failed to attend wearing an appropriate spectacle correction. Whereas there were only four $(1 \cdot 1 \%)$ eyes with $6 / 18$ or poorer vision in the NBW group, this compared with 25 $(6.6 \%)$ eyes in the VLBW group. The different causes of poor monocular vision among the VLBW group are listed in Table 2. Miscellaneous causes of poor monocular vision found in four eyes, included one child who had nystagmus associated with hydrocephalus and another who had oculocutaneous albinism.

\begin{tabular}{ll}
\hline & $\begin{array}{l}\text { No of } \\
\text { eyes }\end{array}$ \\
\hline Strabismic amblyopia & 7 \\
Optic atrophy & 6 \\
ROP & 5 \\
Myopia & 3 \\
Miscellaneous & 4 \\
\hline
\end{tabular}

A concomitant squint was noted in $38(19 \%)$ of the VLBW group and in five $(2 \cdot 5 \%)$ of the NBW group and the difference is highly significant $\left(\chi^{2}=27 \cdot 14, \mathrm{DF}=1, \mathrm{p}<0.001\right)$. A further 10 children had a past history of squint, four of whom had been treated surgically while six responded to conservative treatment. There was no significant difference between the ratio of convergent to divergent squint in the VLBW group $(3 \cdot 4: 1)$ and in the NBW group $(2 \cdot 5: 1)$. Among the VLBW group, six children with birth weight of less than $1000 \mathrm{~g}$ had squint compared with 32 weighing more than $1000 \mathrm{~g}$ (NS).

Squint was associated with optic atrophy (five) and cicatricial ROP (six) in 11 children who were VLBW and with Goldenhar's syndrome in one NBW child. When these structural abnormalities of the visual pathways were excluded there still remained a significant difference in the frequency of squint between the VLBW group and the NBW group $\left(\chi^{2}=18.97, D F=1, p<0.001\right)$. When a further four VLBW children with squint and cerebral palsy (see below) were excluded there were $23(12 \cdot 4 \%)$ children in the VLBW group with strabismus and this was still significantly different from the NBW group $\left(\chi^{2}=9.93\right.$, $\mathrm{DF}=1, \mathrm{p}<0.01)$.

Sixteen children in the VLBW group had cerebral palsy. Eight $(50 \%)$ of these children were noted to have squint and this represented $21 \%$ of the VLBW group with squint. Three of these children were noted to have optic atrophy and a fourth had cicatricial ROP. Therefore only in four $(25 \%)$ of these children could the squint be associated with cerebral palsy alone.

Extraocular movements were studied in all children. One child who was VLBW had bilateral Duane's syndrome while another had a unilateral Brown's syndrome. Both children were orthophoric in the primary position. Among the NBW group one child had nystagmus associated with Goldenhar's syndrome and another had limitation of adduction in one eye. Nystagmus was observed in nine children who were VLBW, five of whom had optic atrophy. Of the remainder one child had nystagmus associated with hydrocephalus, another oculocutaneous albinism and two had cicatricial ROP.

\section{REFRACTION}

A cycloplegic refraction was performed in all but one of the children who were VLBW and all eyes but one in the NBW group. The spherical equivalent value for each child was calculated and their distributions are presented in Figure 1. The mean spherical equivalent of children who were VLBW was $0.99 \mathrm{D}$ (SD 2.47) and $1.67 \mathrm{D}$

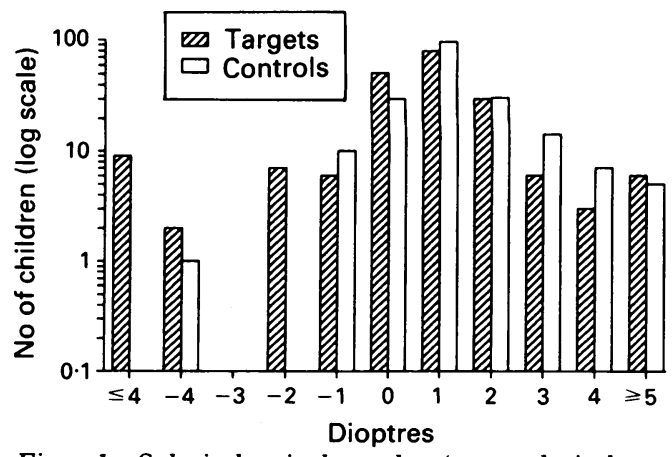

Figure 1 Spherical equivalent values (mean spherical equivalent of two eyes) of children who were of very low and normal birth weight. 
$(\mathrm{SD} 1 \cdot 31)$ for NBW children $(t=3 \cdot 37, \mathrm{DF}=390$, $\mathrm{p}<0.001)$. A minus spherical equivalent value was present in $24(12 \cdot 1 \%)$ children who were VLBW and in $11(5 \cdot 7 \%)$ NBW children $\left(\chi^{2}=\right.$ $4 \cdot 87, \mathrm{DF}=1, \mathrm{p}<0.05$ ).

When children with regressed ROP were excluded from the analysis the mean spherical equivalent of the remaining children was $1.24 \mathrm{D}$ (SD 2.13) and there still remained a significant difference betweem this VLBW group and the NBW group $(t=2 \cdot 40, \quad \mathrm{DF}=373, \mathrm{p}<0.05)$. Although $17(9 \cdot 3 \%)$ children in this VLBW group without regressed ROP had a minus spherical equivalent value, this did not represent a statistically significant difference between this group and the NBW group.

\section{ANTERIOR SEGMENT}

Significant corneal pathology was noted in only one child in the NBW group who had bilateral limbal dermoids associated with Goldenhar's syndrome. One child in the VLBW group had cataracts diagnosed at 3 years of age. Subsequently he had bilateral lensectomy and at the time of examination visual acuity was $6 / 6$ in his right eye and 6/12 in the left with aphakic correction. This child had hypocalcaemia but was neither asphyxiated or hypoglycaemic in the perinatal period. There was no family history of cataract. Bilateral temporal sector lens opacities were also noted in a child with cicatricial ROP.

Visually insignificant lens opacities were also observed. These included Mittendorf dots noted in six (nine eyes) children who were VLBW and eight (10 eyes) NBW children. Other minor changes including multiple dots and sutural lens opacities were noted in five (10 eyes) children in the VLBW group and three (five eyes) NBW controls.

\section{OPTIC ATROPHY}

Optic atrophy was noted in six $(3 \%)$ children who were VLBW. Four of these children with bilateral optic atrophy were severely mentally retarded. Another child had unilateral optic atrophy associated with cicatricial ROP. Lastly a child who initially presented at age 4 with squint was noted to have nystagmus and bilateral optic atrophy at follow-up. Visual acuity was reduced to 6/24 in the right eye with absent pattern visual evoked response. Focal dilatation of the left lateral ventricle on computed tomographic scan was thought to be related to periventricular ischaemia in the perinatal period. There was a history of pre-eclamptic toxaemia during the pregnancy and the child required resuscitation at birth. He subsequently developed necrotising enterocolitis.

Of the six children with optic atrophy three had intraventricular haemorrhage (IVH) and four had seizures in the perinatal period. Children with optic atrophy were also more likely to have had bronchopulmonary dysplasia and hyponatraemia as neonates. However, this group was no more likely to have had fetal distress or poorer Apgar scores than children in the VLBW group without optic atrophy.
REGRESSED ROP

The typical 'dragged disc' of more severe posterior regressed ROP was noted in six (3\%) children. Two of these children weighed less than $1000 \mathrm{~g}$ at birth. In two cases the disease was asymmetrical with only minimal changes and good vision in the fellow eye. Myopia was associated with posterior cicatricial ROP in all but one child with bilateral disease who had an uncorrected vision of $6 / 9$ in the right eye and $6 / 12$ in the left. Although one child was legally blind with the disease no case of total retinal detachment was found.

Indirect ophthalmoscopy was performed in 195 children who were VLBW and all of the children in the NBW group. Evidence of peripheral regressed ROP was noted in seven children who were VLBW. The commonest finding was temporal pigmentation. Vitreoretinal interface abnormalities, areas of avascular retina and lattice degeneration were also noted. Retinal tears in areas of lattice degeneration were present in two children, one of whom required cryopexy. Four of these seven children had significant associated ocular disease; two with myopia and two with squint. In total $13(6.7 \%)$ of the VLBW children were noted to have evidence of regressed ROP. No similar retinal pathology was noted in the NBW children.

Only two children in this study were noted to have acute ROP in the perinatal period. One child developed cicatricial changes while in the other child the disease totally regressed. Another child who had avascular peripheries as a neonate was noted to have similar changes with associated pigmentation on follow-up.

\section{Discussion}

Two hundred (84\%) surviving children, from one neonatal intensive care unit, were examined in this study. This is the most comprehensive controlled follow-up of VLBW children of school age undertaken within the British Isles in recent years. Ocular morbidity was high among the VLBW group and this may be due to bias in the sample since those children with known defects were more likely to attend for ophthalmic examination. However, of the 38 surviving children who did not have an eye examination, at least two were known to have strabismus and one had poor vision.

Binocular visual acuity of $6 / 18$ or worse was recorded in $10(5 \cdot 1 \%)$ or $1: 20$ of the VLBW children. This contrasts with an incidence of visual handicap among children in Northern Ireland of less than $1: 1000 .^{8}$ The frequency of vision worse than $6 / 18$ is also higher than similar follow-up studies of preterm children where frequencies of $1 \%{ }^{9}$ and $2 \cdot 4 \%{ }^{10}$ have been noted. Although a higher rate of poor vision among VLBW children has been reported recently, ${ }^{41}$ Snellen equivalent were not quoted and therefore direct comparison is difficult. No previous follow-up studies of children born preterm have tested reading vision. It is encouraging, especially from the educational viewpoint, that 188 (94\%) children in the VLBW group had reading vision of $\mathrm{N} 6$ or better.

A concomitant squint was detected in 38 
(19\%) children in the VLBW group and strabismic amblyopia was the commonest cause of poor monocular vision. In similar studies of low birth weight groups $19 \%^{3}$ and $22 \cdot 5 \%^{12}$ of children have been noted to have strabismus. When children with associated ocular abnormalities and cerebral palsy were excluded there were 23 . (12.4\%) VLBW children with squint and this is well above the prevalence of $3.5 \%$ found in the general population. ${ }^{13}$ McCormick et $a l^{9}$ found $14 \%$ of children with squint in low birth weight groups when other ocular or cerebral diseases were excluded.

Six $(30 \%)$ children who weighed less than $1000 \mathrm{~g}$ at birth had strabismus and in a recent study of 4 year old children who were ELBW, ${ }^{14}$ $24 \%$ were noted to have strabismus. Although we have noted a relatively high frequency of squint among ELBW children, this did not represent an excess in this group and is in keeping with other reports showing no correlation between squint and birth weight. ${ }^{10}$ is

Nystagmus was noted in nine children in the VLBW group, the majority of whom had optic atrophy or cicatricial ROP. In previous followup studies ${ }^{416}$ of low birth weight children where nystagmus has been noted it has invariably been associated with either ocular or cerebral disease.

Of the 16 children with cerebral palsy $50 \%$ were noted to have squint and this is in agreement with previous reports ${ }^{17}{ }^{18}$ of the frequency of strabismus associated with cerebral palsy. The contribution that children with cerebral palsy make to the overall frequency of squint among VLBW children depends on the frequency of cerebral palsy in that group. Whereas $8 \%$ of VLBW children in our study had cerebral palsy, and this accounted for $21 \%$ of the cases of strabismus, Keith and Kitchen ${ }^{3}$ noted $13 \cdot 5 \%$ of children with cerebral palsy accounting for $33 \cdot 3 \%$ of their cases of squint.

Eyes of children in the VLBW group were significantly more myopic with a mean refraction of $0.99 \mathrm{D}$ than those in the NBW group whose mean refraction was $1.67 \mathrm{D}$. The latter falls between the general population mean ocular refraction of $1.25 \mathrm{D}$ for boys and 2.03 for girls at 9 years of age. ${ }^{19}$ Fledelius $^{10}$ also noted a myopic shift among a premature group with an average refraction of $0.75 \mathrm{D}$ compared to a mature group with a mean refraction of $1.53 \mathrm{D}$. Most other reports have concentrated on the percentage of eyes of children with a minus refraction and from $13 \%$ to $23 \%^{10} 1220$ of children born preterm have been found to have myopia. The frequency of myopia in our study was $12 \cdot 1 \%$ and in keeping with these reports was significantly higher than the control group.

The relationship between myopia and cicatricial ROP is well established. ${ }^{2122}$ Some follow-up studies of preterm infants have also noted that myopia is uncommon when cases of ROP are excluded. ${ }^{23}{ }^{24}$ When we exclude eyes of children with regressed ROP from the VLBW group, there was still a significant difference in the mean spherical equivalent between this group and the control group. A minus spherical equivalent was present in $9 \cdot 3 \%$ of eyes of children in the VLBW group without ROP and this compares with a recent report ${ }^{12}$ where $10 \%$ of a similar group of children had myopia. In contrast, it has been suggested ${ }^{25}$ that children born preterm with high refractive errors and ophthalmologically normal fundi, may in fact have had acute ROP in infancy that completely regressed. We have found that preterm children without clinical signs of regressed ROP tend towards myopia and it has been noted that this myopia is mainly corneal in nature. ${ }^{10}$ Light may have an inhibitory effect on the growth of the eye $^{26}$ and the thermal deficit resulting from premature birth may also adversely affect corneal flattening ${ }^{27}$ which normally proceeds rapidly in the final weeks of gestation.

One child who was VLBW was noted to have isolated cataracts. Although this child had hypocalcaemia in the perinatal period it is unlikely this was the underlying cause of the lens opacities. Hypocalcaemia occurred in up to $68 \%$ of neonates during this period and these cataracts were not diagnosed until 3 years of age. Another child was noted to have cataract associated with cicatricial ROP. The overall frequency of lens opacities of $1 \%$ is similar to other studies of children born preterm ${ }^{1028}$ and contrasts with a prevalence of visually significant cataract in children, in Northern Ireland, of $0.03 \% .^{8}$ There was no difference in the frequency of visually insignificant lens opacities between the two groups in this study and it has been noted that such changes are so minor as to be considered physiological. ${ }^{29}$

Optic atrophy was noted in six (3\%) VLBW children and this compares with recent reports where $2 \cdot 7 \%$ of $\mathrm{VLBW}^{3}$ and $4 \%$ of $\mathrm{ELBW}^{1+}$ infants were found to have optic atrophy. Perinatal hypoxia may precipitate optic atrophy but this is an uncommon sequel of this metabolic disturbance $^{30}$ and we have found that children with optic atrophy were no more likely to have had fetal distress or poorer Apgar scores than the remainder of the VLBW children. Three children with optic atrophy were noted to have clinically significant IVH in the neonatal period and another child had evidence of previous periventricular ischaemia. The latter had many of the risk factors associated with this condition including pre-eclamptic toxaemia and necrotising enterocolitis. ${ }^{31}$ Damage to the optic radiation and visual cortex in the perinatal period from hypoxic/ischaemic lesions or IVH may have resulted in trans-synaptic degeneration and optic atrophy in these children. However, although trans-synaptic retrograde degeneration has been noted in the visual system of adolescent primates $^{32}$ no evidence exists at present for a similar mechanism in humans.

Significant cicatricial ROP was present in six (3\%) of VLBW children rising to $10 \%$ for those weighing less than $1000 \mathrm{~g}$. Although there were no children who had bilateral retinal detachments from ROP, one child was registered blind. Of these six children with posterior cicatricial ROP only one child was noted to have acute ROP in the neonatal period. As many of these neonates were seriously ill for a considerable time their initial ophthalmological assessment was often delayed and acute stages of the disease may have regressed by the time they were examined. Subtle changes of cicatricial disease may have 
been overlooked at these later examinations.

In recent studies $1 \%^{33}$ and $10 \%^{3}$ of VLBW children have been noted to have cicatricial ROP. Variations in the reported rates of this condition may be influenced by the survival rate of the most premature infants and up to $42 \%$ of children who were $\mathrm{ELBW}^{34}$ have been found to have cicatricial ROP. In our study only $10 \%$ of children weighed less than $1000 \mathrm{~g}$, contributing to a low overall frequency of cicatricial ROP. In contrast to the severe blinding cicatricial disease during the epidemic years, ${ }^{35}$ cicatricial ROP during the period studied in this neonatal unit appears much less severe. Perhaps better control of oxygen therapy with blood and transcutaneous gas monitoring, and overall attention to homoeostasis of these infants has contributed to the low rate of less severe cicatricial disease in this unit.

Seven VLBW children were noted to have peripheral retinal changes and since there were no analogous retinal changes found in any of the NBW children it is highly probable that these changes represent regressed ROP. The commonest finding was peripheral pigmentation which may represent the region of a previous mesenchymal shunt found in acute ROP or an area of resolved retinal detachment. A retinal tear was noted in an area of lattice in one of these patients and Tasman ${ }^{36}$ has emphasised the need to examine these children for peripheral retinal abnormalities. Two cases of myopia and two of squint were also noted among this group with peripheral retinal findings. Previous studies ${ }^{25}{ }^{37}$ have also noted a higher incidence of ocular abnormalities among children with regressed ROP and the need to follow this at-risk group has been stressed.

Despite the improved prospects for VLBW children they still have a significant excess of visual problems. Strabismus, refractive errors, and cicatricial ROP are well recognised causes of visual morbidity among this group but this study has also highlighted the problem of optic atrophy in these children. The prevalence of regressed ROP remains low for the period studied in this neonatal intensive care unit. Severe blinding cicatricial ROP was also rare and this may be accounted for by a smaller number of ELBW children in the study and good perinatal medical care. Children born preterm have an increased risk of long term ophthalmological problems. It is important that they should have regular assessments so that potentially treatable problems such as strabismic amblyopia and refractive errors can be identified.

We thank Dr Don Sykes, Department of Psychology, Queen's University, Belfast who performed the statistical analysis. This work was funded by a grant from the DHSS for Northern Ireland.

1 Mutch L, Newdick M, Lockwick A, Chalmers I. Secula changes in rehospitalisation of very low birth weight infants. Pediatrics 1986; 78: 164-71.

2 Levene MI, Dubowitz LMS. Low birth weight babies. Long term follow-up. Brf Hosp Med 1982; 28: 487-91.

3 Keith CG, Kitchen WH. Ocular morbidity in infants of very low birth weight. Br $\mathcal{F}$ Ophthalmol 1983; 67: 302-5.

4 Gibson NA, Fielder AR, Trounce JQ, Levene MI. Ophthalmi findings in infants of very low birth weight. Dev Med Child Neurol 1990; 32: 7-13.

Sheridan M. The STYCAR graded balls vision test. Dev Med Child Neurol 1973; 15: 423-32.

6 International Committee for the Classification of the Late Stages of Retinopathy of Prematurity. An international classification of retinopathy of prematurity: II. The classification of retinal detachment. Arch Ophthalmol 1987; 105: 906-12.

7 SPSS-X. User's guide. 3rd Ed. Chicago: SPSS, 1988

8 Bryars JH An investigation of the visually handicapped children in Northern Ireland. The Queen's University Belfast: MD Thesis, 1977 .

9 McCormick AQ, Tredger EM, Dunn HG, Grunau RVE. Ophthalmic disorders. In: Dunn HG, ed. Sequelae of low Ophthalmic disorders. In: Dunn HG, ed. Sequelae of low 1986: 127-46.

10 Fledelius H. Prematurity and the eye. Acta Ophthalmol 1976; Supp 128: 127-245.

11 Van Hof-van Duin J, Pott JW. Visual impairment in children with very low birthweight at 5 years of age. IOVS 1989; 3: 496

12 Cats BP, Tan KEWP. Prematures with and without regressed retinopathy of prematurity: comparison of long-term. (6-10 years) ophthalmological morbidity. 7 Pediatr Ophthalmol Strabismus 1989; 26: 271-5.

13 Alberman ED, Butler NR, Gardiner PA. Children with squints. A handicapped group? Practitioner 1971; 206: 501-

14 Burgess P, Johnson A. Ocular defects in infants of extremely ow birth weight and low gestational age. Br $\mathcal{F}$ Ophthalmol 1991; 75: 84-7.

15 Drillien CM. The growth and development of the prematurely born infant. Edinburgh: Livingstone, 1964.

16 Hammer HM, Noble BA, Harcourt RB, Congdon PJ. Ophthalmic findings in very low birth weight children. Trans Ophthalmol Soc UK 1985; 104: 329-31.

17 Douglas A ed. Cerebral palsy in childhood and adolescence: a medical, psychological and social study. London: E \& S Livingstone, $1961 ; 197-241$

18 Smith VH. A survey of strabismus in cerebral palsy. In: Visual disorders in cerebral palsy. Little Club Clinics in Developmental Medicine No 9. London: Spastics Society with Heinemann, 1963: 22-36.

19 Sorsby A, Benjamin B, Sheridan M. Refraction and its components durng the growth of the eye from the age of three. London: Med Res Counc Spec Rep Ser No 301, 1961: 1-34.

20 Eames TH. Eye conditions among children of premature, fullterm and hypermature birth. Am f Ophthalmol 1946; 29: 57 63.

21 Fletcher MC, Brandon S. Myopia of prematurity. Am $\mathcal{f}$ Ophthalmol 1955; 40: 474-81

22 Gunn TR, Easdown J, Outerbridge EW, Aranda JV. Risk factors in retrolental fibroplasia. Pediatrics 1980 ; 65: 1096100.

23 Kalina R. Ophthalmic examination of children of low birth weight. Am 7 Ophthalmol 1969; 67: 134-6.

24 Nissenkorn I, Yassur Y, Mashkowski D, Sherf I, Ben-Sira I. Myopia in premature babies with and without retinopathy of prematurity. Brf Ophthalmol 1983; 67: 170-3.

25 Kushner BJ. Strabismus and amblyopia associated with regressed retinopathy of prematurity. Arch Ophthalmol regressed retinopath

26 Weale RA. A biography of the eye. London: HK Lewis, 1982.

27 Fielder AR, Levene MI, Russell-Eggitt IM, Weale RA Temperature - a factor in ocular development? Dev Med Child Neurol 1986; 28: 279-84.

28 McDonald AD. Children of very low birth weight. MEIU Monograph No 1 . London: Spastics Society with Heinemann, 1967: 1-83.

29 Bellows J. Frequency and location of punctate opacities in three hundred young crystalline lenses. Arch Ophthalmol 1945; 33: 229-36.

30 Hoyt CS. Optic atrophy and cortical blindness. In: Insenber SJ, ed. The eye in infancy. Chicago: Year Book Medical Publishers, 1989: 327-9.

31 de Vries LS, Larroche JC, Levene MI. Cerebral ischaemi lesions. In: Levene MI, Bennett MJ, Punt J, eds. Fetal and neonatal neurology and neurosurgery. Edinburgh: Churchill neonatal neurology and neur

32 Van Buren JM. Trans-synaptic retrograde degeneration in the visual system of primates. $\mathcal{F}$ Neurol Neurosurg Psychiat 1963

$33 \mathrm{Ng}$ YK, Fielder AR, Shaw DE, Levene MI. Epidemiology of retinopathy of prematurity. Lancet 1988; ii: 1235-8.

34 Shahinian L, Malachowski N. Retrolental fibroplasia. A new analysis of risk factors based on recent cases. Arch Ophthal mol 1978; 96; 70-4.

35 Wright FH, Blough RR, Chamberlin A, Ernest T, Halstea WC, Meier P, et al. Controlled follow-up study of smal prematures born from 1952 through 1956. Am $\mathcal{F}$ Dis Child 1972; 124: 506-12.

36 Tasman W. Late complications of retrolental fibroplasia Ophthalmology 1979; 86: 1724-40.

37 Schaffer DB, Quinn Ge, Johnson L. Sequelae of arrested mild retinopathy of prematurity. Arch Ophthalmol 1984; 102 